DE

M E D I C I N A

T R O P I C A L

$\mathrm{DE}$

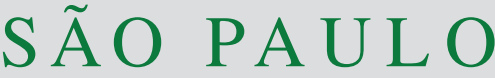

JOURNAL OF THE SÃO PAULO INSTITUTE OF TROPICAL MEDICINE

'Universidade Federal Fluminense, Faculdade de Medicina, Niterói, Rio de Janeiro, Brazil

Correspondence to: Laura da Cunha Ferreira Universidade Federal Fluminense, Faculdade de Medicina, Av. Marquês do Paraná, 303, CEP24033-900, Niterói, RJ, Brazil

E-mail: lauracunha4@ hotmail.com

Received: 16 July 2019

Accepted: 26 September 2019

\section{Influence of vaccine-preventable diseases and HIV infection on demand for an infectious diseases service in Rio de Janeiro State, Brazil, over 22 years - Part II (1995-2016)}

\author{
Laura da Cunha Ferreira ${ }^{1}$, Sérgio Setúbal' ${ }^{1}$, Luiz Sérgio Keim¹, Solange \\ Artimos de Oliveira 1
}

\section{ABSTRACT}

Patients' data during daily clinical care are extremely important for improving the allocation of healthcare resources and for assessing healthcare demands. The prospective gathering of these data over decades allowed us to describe the trends of infectious diseases in a tertiary hospital. The results concerning the period between 1965 and 1994 described the exponential increase in the incidence of HIV infection and its important effects on our institutional mortality. The present study describes the demand for the same hospital between 1995 and 2016. There were 4,691 admissions and the main causes of admissions were, in descending order, HIV infection $(1,312,28.0 \%)$, noninfectious diseases $(447,9.5 \%)$, meningoencephalitis $(432,9.2 \%)$, soft tissue infections $(427 ; 9.1 \%)$, tuberculosis $(272$, $5.8 \%)$, pneumonias $(212,4.5 \%)$ and leptospirosis $(212,4.5 \%)$. There were 864 readmissions; most due to HIV infections $(65.2 \%)$. The institutional mortality fell from $16.9 \%$ in the first two years to $5.0 \%$ in the last two years of the study. The case-fatality rates among the HIV patients decreased from more than $40 \%$ to approximately $5 \%$ over the study period. In the last two decades, the hospital experienced a decrease in demand due to vaccine-preventable diseases. The demand for children has fallen and the demand for patients over the age of 50 has increased. These results reflect the improvement in public health standards over more than half a century and the positive effects of the National Immunization Program. They also illustrate the sharp decline in the HIV case-fatality rate after the introduction of combined antiretroviral therapy.

KEYWORDS: Health services needs and demand. Nursery. Infectious diseases. Rio de Janeiro. Hospitalizations. Vaccine-preventable diseases. Infectiology.

\section{INTRODUCTION}

The last four decades in Brazil have been marked by important changes in hospital demand due to infectious diseases. These changes may be largely attributed to the most relevant action of the Brazilian Ministry of Health (MS) over this period, mass vaccination efforts that started with the inception of the National Immunization Program 40 years ago ${ }^{1}$. The Brazilian demographic and economic transition and the emergence of the acquired immune deficiency syndrome (AIDS) played an important role in these changes, as well ${ }^{2}$.

Hospital demand studies are scarce in the medical literature, and those concerning tertiary teaching hospitals are even scarcer. However, understanding the trends of the hospital demand for infectious diseases care over recent years is crucial for the needed rethinking of public policy strategies for sanitation, immunization, education 
and allocation of human and material healthcare resources. Hospital admissions are a key event in health care delivery. They may vary over time and knowing their seasonal and secular variation is crucial for tailoring the response to predictable demands ${ }^{3}$. In addition, there are unpredictable demands due to epidemic infectious diseases that may cause a sudden increase in the need of hospital beds and healthcare workers. In this situation, knowing the hospital sectors from which labor and resources can be relocated is also crucial ${ }^{4}$.

Setúbal et al. ${ }^{2}$ studied three decades of demand due to infectious diseases in the Infectiology Service of the Hospital Universitario Antonio Pedro (HUAP), Niteroi, Rio de Janeiro State, Brazil, from the inception of this service in 1965 until 1994. From 1965 to 1984, the authors noted a continuous decrease in hospitalizations for vaccine-preventable diseases and an initial positive trend in the institutional mortality, which dropped from $31 \%$ in 1965 to $10 \%$ in 1984 . However, the institutional mortality increased again since 1985, due to the progressive increase in hospitalizations due to HIV infection, reaching $15 \%$ in 1994. The increasing importance of the demand due to HIV infection was emphasized by the authors, as only 10 years after the first hospital admission in 1985, HIV infection was one of the five most frequent diagnoses among the 8,630 patients admitted in all 30 years of the study. These five most frequent diagnoses were tetanus (11.2\%), bacterial meningoencephalitis (8.3\%), diphtheria (7.7\%), measles (5.7\%) and HIV infection (5.3\%).

The overall objectives of the present study were to describe the demand for the same service in subsequent years, i.e., from 1995 to 2016 and to compare these results with those reported by Setúbal et al. ${ }^{2}$ in the previous 30 years, considering the influence of the National Immunization Program and the emerge of the HIV epidemic.

\section{MATERIAL AND METHODS}

This is a descriptive study, and all the patients admitted to the HUAP Infectiology Service from 1995 to 2016 were eligible. Patients with unknown final diagnoses were excluded.

The HUAP was opened in 1951 as a municipal community hospital. In 1964, it was transferred to the Universidade Federal Fluminense (UFF) as a teaching hospital. It is now a tertiary/quaternary teaching hospital committed mainly to the care of referred patients with medical problems beyond the resolving capacity of neighboring hospitals. Its coverage area corresponds to a population estimated at over two million inhabitants in the so-called Metropolitan Region II, a conurbation that encompasses Niteroi, Sao Goncalo, and neighboring municipalities ${ }^{5}$. The Infectiology Service has kept a medical file (now computerized) with data from all the hospitalized patients since the last months of 1964.

The variables studied were sex, age, address, final diagnosis, re-hospitalizations, clinical outcome (discharge, hospital transfer or death), year of hospitalization and secondary diagnoses. These data were imported into an Excel spreadsheet and analyzed by the SPSS Statistics Software, version 18.0 for Windows (IBM, USA). Results were expressed as frequencies, percentages, and means or medians, according to their distribution. Categorical variables were analyzed by means of chi-square tests, where $\mathrm{P}<0.05$ was considered significant. The Epi Info software version 7.2.2.6 (Centers for Diseases Control and Prevention, Atlanta, Georgia, USA) was also used for analyses.

Institutional mortality was calculated by dividing the number of deaths by the number of patients admitted to the service in the same period. To facilitate the interpretation of the results and the comparison with the previous study ${ }^{2}$, the institutional mortality was presented as the number of deaths per 100 cases. As in the former study, a distinction was made between the number of patients and the number of admissions; the number of admissions also includes the readmissions of the same patient.

The final diagnoses were grouped into 12 categories: HIV infection, tuberculosis, meningoencephalitis, soft tissue infections, pneumonias, noninfectious diseases, leptospirosis, tetanus, whooping cough, measles, diphtheria and others (all the diagnoses whose frequencies were less than $2 \%$ ).

This research was approved by the Research Ethics Committee of the Faculty of Medicine of the UFF under the $\mathrm{N}^{\circ}$ CAAE 61210216.7.0000.5243.

\section{RESULTS}

\section{Overall results of hospitalization}

There were 4,691 hospital admissions to the Infectiology Service from January 1, 1995 to December 31,2016 . Five patients were excluded due to the lack of a final diagnosis. Thus, the study population consisted of 3,822 patients corresponding to 4,686 hospital admissions, of which 864 were readmissions.

Among the 4,686 admissions, there were 2,763 (59\%) hospital admissions of male patients and 1,923 (41\%) admissions of female patients. Patients' ages ranged from less than one to 100 years old, with a mean of 36.6 years and a standard deviation of 21.3 years. The median age was 36 years, and the interquartile range was between 
20.0 and 51.0 years. The municipality of residence at the time of admission was recorded in only 4,512 of the 4,686 hospitalizations. Niteroi $(1758 ; 39.0 \%)$ and Sao Goncalo $(1644 ; 36.4 \%)$ were the most frequent cities.

The 175 patients that were less than 15 years old and who were admitted in the first two years of the study corresponded to $27.0 \%$ of the 648 admissions in that period. In the last four biennia, this percentage was less than $10.0 \%$, and in the last biennium, it fell to $2.8 \%$ or eight of the 283 admissions. The 52 patients aged 60 years or older corresponded to $8.0 \%$ of the 648 cases in the first two years of the study; admission in this age group increased to 97 of the 283 admissions (34.3\%) in the last two years (Figure 1).

\section{Most frequent diagnoses}

The most frequent diagnoses were, in descending order, HIV infection $(1,312 ; 28 \%$ of admissions), followed by cases that do not include HIV co-infected patients: noninfectious diseases (447; $9.5 \%$ of admissions), meningoencephalitis (432; $9.2 \%$ of admissions), soft tissue infections (427; $9.1 \%$ of admissions), tuberculosis (272; $5.8 \%$ of admissions), pneumonia (212; $4.5 \%$ of admissions), and leptospirosis $(212 ; 4.5 \%$ of admissions) (Table 1$)$. Among the 864 hospital readmissions, the most common final diagnosis was HIV infection $(563 ; 65.2 \%)$.

The main causes of hospital admission varied throughout

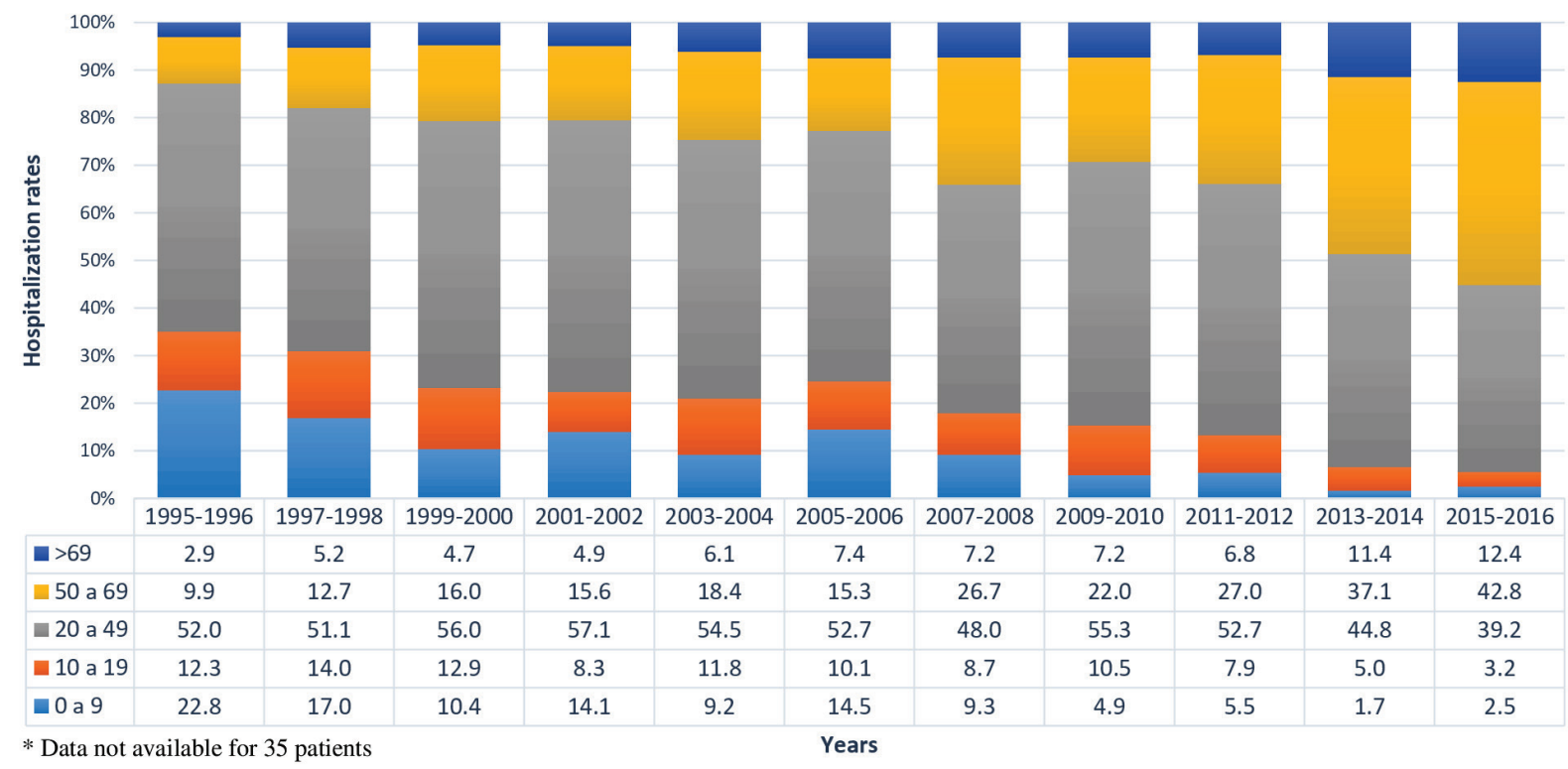

Figure 1 - Hospitalization rates of 4,651* admissions by age group according to the biennium (1995-2016).

Table 1 - Main diagnoses of hospital admissions between 1995-2016.

\begin{tabular}{|c|c|c|c|c|c|c|c|c|c|c|c|c|}
\hline Main Diagnosis & $\begin{array}{c}1995- \\
1996\end{array}$ & $\begin{array}{c}1997- \\
1998\end{array}$ & $\begin{array}{l}1999- \\
2000\end{array}$ & $\begin{array}{l}2001- \\
2002\end{array}$ & $\begin{array}{l}2003- \\
2004\end{array}$ & $\begin{array}{c}2005- \\
2006\end{array}$ & $\begin{array}{l}2007- \\
2008\end{array}$ & $\begin{array}{l}2009- \\
2010\end{array}$ & $\begin{array}{l}2011- \\
2012\end{array}$ & $\begin{array}{c}2013- \\
2014\end{array}$ & $\begin{array}{l}2015- \\
2016\end{array}$ & N (\%) \\
\hline AIDS & 184 & 105 & 118 & 128 & 133 & 152 & 116 & 89 & 112 & 123 & 52 & $1,312(28.0)$ \\
\hline Non-infectious causes & 52 & 33 & 44 & 25 & 38 & 33 & 33 & 21 & 30 & 71 & 67 & $447(9.5)$ \\
\hline Meningoencephalitis & 119 & 94 & 47 & 48 & 37 & 34 & 16 & 7 & 15 & 5 & 10 & $432(9.2)$ \\
\hline Soft tissue infections & 46 & 33 & 48 & 55 & 47 & 43 & 28 & 24 & 38 & 38 & 27 & $427(9.1)$ \\
\hline Tuberculosis & 21 & 18 & 12 & 22 & 27 & 31 & 28 & 30 & 34 & 28 & 21 & $272(5.8)$ \\
\hline Pneumonia & 23 & 18 & 19 & 21 & 29 & 18 & 12 & 12 & 21 & 18 & 21 & $212(4.5)$ \\
\hline Leptospirosis & 48 & 33 & 27 & 26 & 25 & 25 & 12 & 5 & 8 & 3 & 0 & $212(4.5)$ \\
\hline Varicella & 10 & 10 & 16 & 10 & 13 & 35 & 10 & 8 & 12 & 10 & 1 & $135(2.9)$ \\
\hline Dengue & 2 & 3 & 5 & 19 & 0 & 3 & 25 & 25 & 23 & 5 & 0 & $110(2.4)$ \\
\hline Snake bite & 10 & 1 & 9 & 11 & 11 & 10 & 1 & 13 & 13 & 13 & 9 & $101(2.2)$ \\
\hline Herpes zoster & 7 & 6 & 17 & 5 & 8 & 14 & 8 & 9 & 11 & 8 & 4 & $97(2.1)$ \\
\hline Frequency < $2 \%$ & 129 & 114 & 92 & 98 & 90 & 88 & 44 & 61 & 50 & 92 & 71 & $929(19.8)$ \\
\hline TOTAL & 651 & 468 & 454 & 468 & 458 & 486 & 333 & 304 & 367 & 414 & 283 & $4,686(100)$ \\
\hline
\end{tabular}


the studied years according to Figure 2. HIV infection remained the main cause of hospitalization throughout the study period, except in the last year, when it was overcome by noninfectious diseases. There was a progressive decrease in the number of hospitalizations due to meningoencephalitis, of which 363 (84.0\%) occurred in the first decade of the study. There was no hospital admission for this cause in 2016.

Hospital admissions for soft tissue infections and pneumonias occurred regularly throughout the study period. Tetanus accounted for only 18 admissions, and in the last nine years, there was only one admission, in 2012, due to this disease in a 64-year-old man.

There were 14 hospital admissions due to diphtheria, mostly in the first three years of the study and in the age group from 1 to 14 years old $(12 ; 85.7 \%)$. If it were not for the single diphtheria admission in 2007 , the ward could have been considered free of this disease since 1999.

There were only nine measles diagnoses during the 21 years of the study, eight of them in 1997 and one in 1998. Six $(67.0 \%)$ measles patients were young people aged 20 to 29 years.

Sixteen $(80.0 \%)$ of the 20 admissions for whooping cough involved children under one year of age. The highest number occurred in 2011 with five admissions. The last admission for whooping cough was in 2013.

There were only three hospitalizations for typhoid fever in 1997, 1998 and 2003.

Among the 18 patients hospitalized for tetanus, there were four $(22.2 \%)$ deaths, all in patients over 50 years of age; one $(7.1 \%)$ of the 14 patients admitted for diphtheria died (a one-year-old child); one (5.0\%) of the 20 patients admitted for whooping cough died (also a child under one year old). None of the nine patients with measles died.

There were 212 hospital admissions (209 patients and three readmissions) for leptospirosis. There was an important decline in admissions due to this disease in the last 10 years of the study, and no cases occurred in 2015 and 2016. Most patients were male $(194,91.5 \%)$ and adults, aged 20 to 49 years $(135,64.6 \%)$. Thirty-four patients died of leptospirosis (16.3\%), of whom five were women $(27.7 \%)$ and 29 were men $(15.2 \%)(\mathrm{p}=0.29)$. There were no deaths in patients under 20 years old. A trend towards higher case-fatality rates was observed in older age groups (chi square for trend $=7.8, \mathrm{p}=0.0006$ ).

\section{AIDS related diseases}

The main opportunistic diseases responsible for the HIV infection hospitalizations were neurotoxoplasmosis $(170 ; 13.0 \%)$, pneumocystosis $(107 ; 8.2 \%)$, pulmonary $(98 ; 7.5 \%)$ and extrapulmonary $(64 ; 4.9 \%)$ tuberculosis, esophagitis $(38 ; 2.9 \%)$, skin and soft tissue infections (38; $2.9 \%)$, herpes zoster (36; 2.8\%), Kaposi's sarcoma $(33 ; 2.5 \%)$, cryptococcal meningoencephalitis $(31 ; 2.4 \%)$, lymphoma/leukemia $(31 ; 2.4 \%)$ and diarrhea $(31 ; 2.4 \%)$. The only opportunistic infection with a tendency to increase was tuberculosis, which corresponded to 33 opportunistic infections from 1995 to 2000 (21.9\%) and 50 opportunistic infections from 2011 to 2016 (59.5\%).

The HIV infection related case-fatality rate was $26.3 \%$ (197 deaths in 749 patients): 65 female patients (24.2\%) and 132 male patients died (27.6\%) ( $>$ > 0.05). The HIV infection case-fatality rate decreased from $40.0 \%$ in 1995 to $5.0 \%$ in 2016. It was highest among adults aged 30 to 39 years $(55 ; 27.9 \%)$.

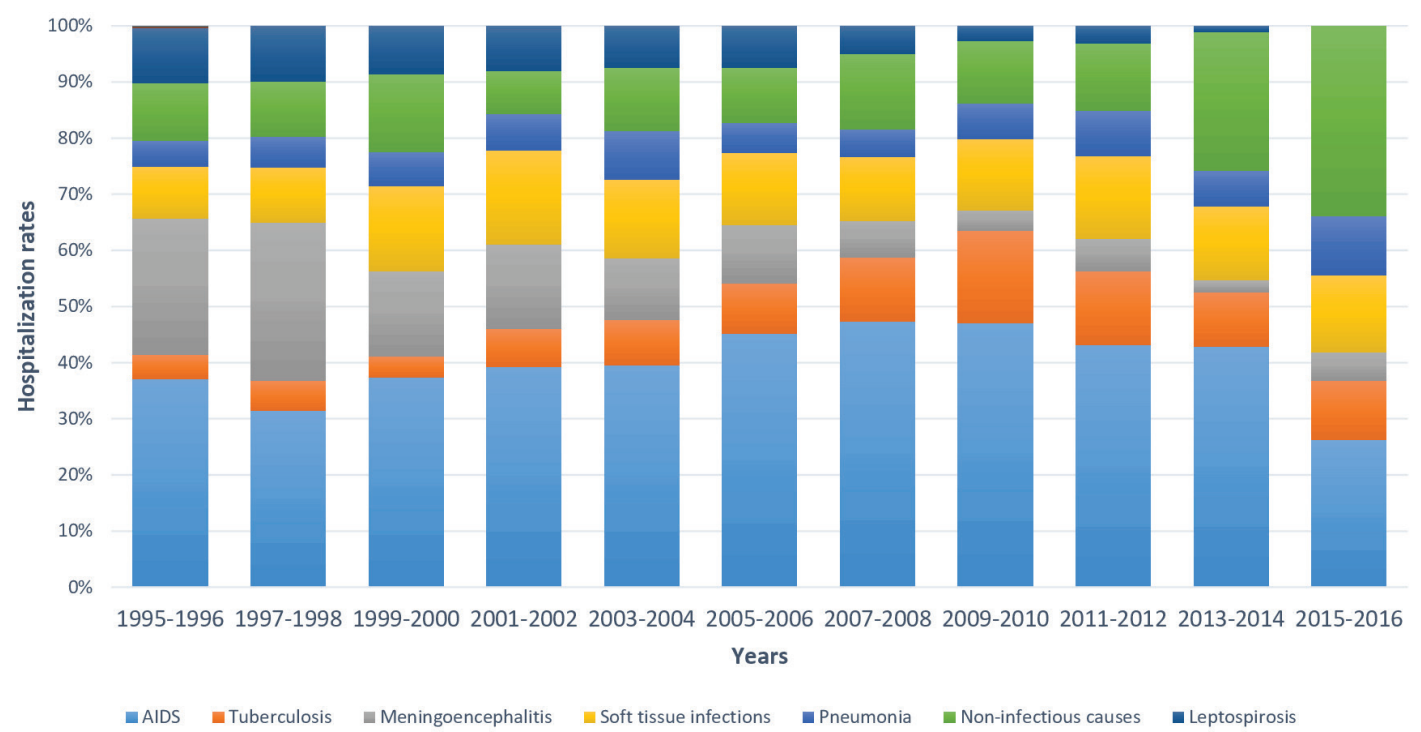

Figure 2 - Main causes of hospital admissions over the years (1995-2016). Number of cases 3,319. 


\section{Institutional mortality}

The institutional mortality was $11.3 \%$ in the whole study period. There were 432 deaths, 281 (65\%) among men $(\mathrm{p}=0.006)$. The overall institutional mortality was $12.5 \%$ among male patients and $9.6 \%$ among female patients. Overall, institutional mortality declined significantly over the years, falling from $16.9 \%$ in 1995-1996 to $5.0 \%$ in the last two years of the study (Figure 3 ). The outcome of six patients was not determined $(0.16 \%)$.

The overall institutional mortality was compared to the institutional mortality calculated by excluding the HIV-infected patients (Figure 4). HIV infection contributed to the maintenance of higher levels of institutional mortality from the beginning of this study until the 2013-2014 biennium, when the influence of deaths due to HIV infection was no longer perceptible.

\section{DISCUSSION}

The continuous collection of data over many years and the follow-up of a large number of patients made it possible, in the present study, to detect nosological, populational and epidemiological changes for over 40 years, corroborating the effectiveness of the National Immunization Program. There was a dramatic reduction in vaccine-preventable diseases and in diseases related to the lack of public sanitation measures. At the same time, there was an increase of HIV infection cases and of hospital admissions related to noninfectious diseases; the latter became the most frequent diagnoses in the last four years of the study.

The top five causes of hospitalization reported by Setúbal et $a .^{2}{ }^{2}$ were tetanus (11.2\% of admissions), bacterial meningoencephalitis $(8.3 \%)$, diphtheria $(7.7 \%)$, measles (5.7\%), and HIV infection (3\%). All other causes of hospital admission had frequencies below $5.0 \%$. HIV infection had an exceptional prevalence in that study, considering that it was present only in the last ten of the 30 years studied. In the present study, only HIV infection remained one of the main causes for hospital admission, accounting for $28 \%$ of admissions from 1995 to 2016 . The other main diagnoses were noninfectious diseases $(9.5 \%)$, meningoencephalitis

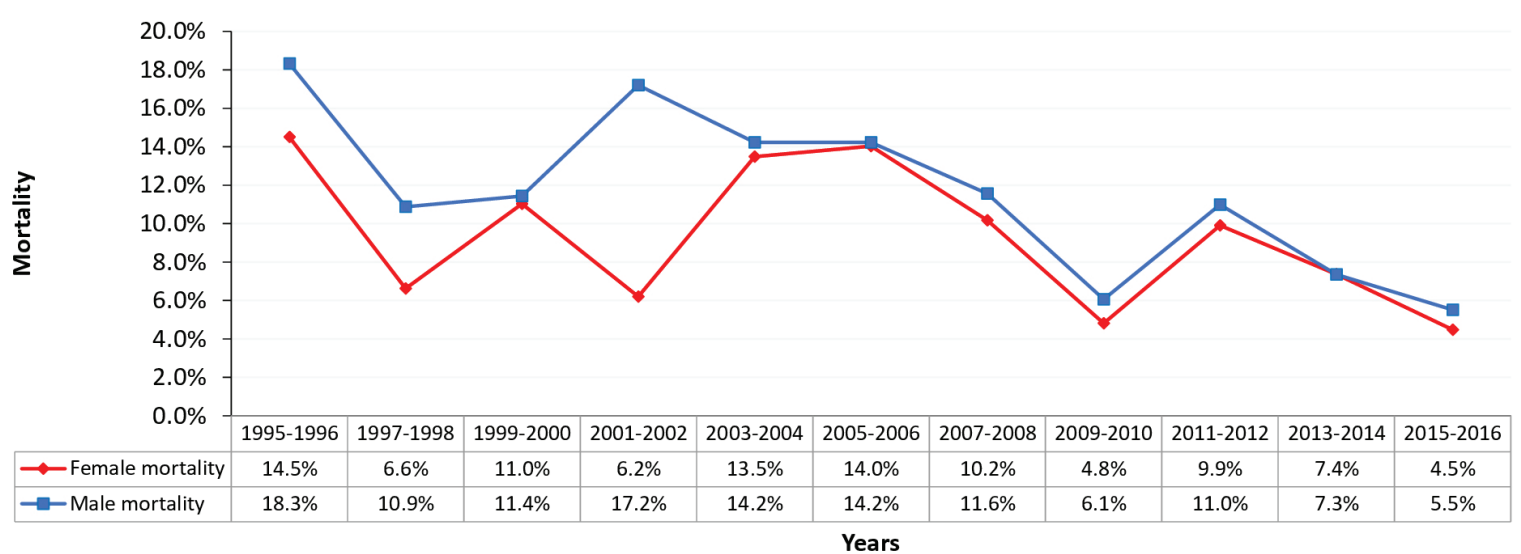

Figure 3 - Institutional mortality according to the hospitalization period and stratified by sex (1995-2016).

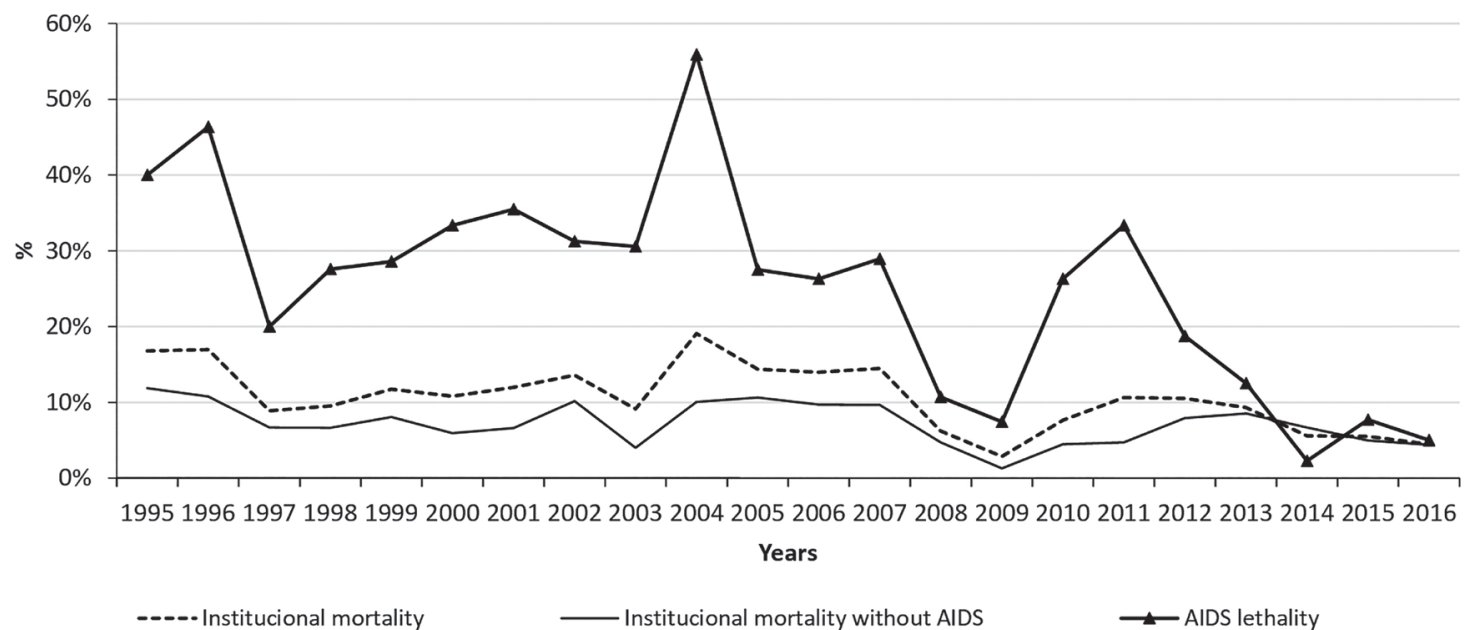

Figure 4 - Impact of AIDS on the institutional mortality (1995-2016). 
of any etiology $(9.3 \%)$, soft tissue infections $(9.1 \%)$ and tuberculosis $(5.8 \%)$.

The increasing effectiveness of the National Immunization Program, established in $1973^{1,6}$, resulted in a dramatic decrease in the incidence of vaccinepreventable diseases and a consequent reduction of hospital admissions due to diseases such as the measles, diphtheria and tetanus. There were only nine measles admissions in the present study, of which the last one occurred in 1998, while Setúbal et al. ${ }^{2}$ reported 491 (5.7\%) admissions from 1965 to 1994 . Measles control requires high vaccination coverages, as outbreaks are possible even when only $10 \%$ of the population is susceptible ${ }^{7}$. In 1997, Brazil experienced a measles epidemic. During that epidemic, the HUAP Infectiology Service detected 21 of the 45 cases of measles confirmed in the Municipality of Niteroi, emphasizing its potential role as a sentinel of nosological trends in this geographical area ${ }^{8}$.

The first National Vaccination Calendar, instituted in 1977, made four vaccines mandatory in the first year of life: BCG; oral polio (OPV); diphtheria, tetanus and pertussis (DTP) as well as measles. In 1986, the hepatitis B vaccine was added. Only in 1995, the triple viral vaccine (against measles, mumps and rubella) was added to schedule. The Measles Elimination and Control Plan began in 1992 and resulted in the interruption of the autochthonous circulation of the virus in $2000^{1}$. In February 2018, a measles outbreak was reported in Roraima State, a Northern State bordering Venezuela. Favored by low vaccine coverages, it rapidly spread to 11 of the 27 Brazilian states and 10,262 cases were confirmed by laboratory and epidemiological criteria until December $2018^{9}$.

The success of the National Immunization Program was remarkable. Setúbal et al. ${ }^{2}$ documented 958 hospitalizations for tetanus between 1965 and 1994, while the same disease caused only 18 hospitalizations between 1995 and 2016, a $98.1 \%$ drop. Setubal et al. ${ }^{2}$ has also reported 654 admissions for diphtheria and 99 for whooping cough, while the present study recorded only 14 admissions for diphtheria and 20 for whooping cough, corresponding to $97.1 \%$ and $79.8 \%$ drop, respectively. The few cases of diphtheria documented in the present study were concentrated in the first three years of the study period. Notwithstanding its lower frequency in the present study ( 20 cases, compared to the 99 cases reported by Setúbal et al. ${ }^{2}$ ), whooping cough cases had a regular distribution throughout the study period, with a slight increase in hospital admissions coinciding with the increase in the incidence of this disease in Brazil as a whole, between 2011 and $2015^{10}$.

Comparing the present study with that of Setúbal et al. ${ }^{2}$, it may be noted that the number of hospital admissions for meningoencephalitis showed the greatest reduction. Having been the main cause of admissions $(1,611$; $18.7 \%$ ), meningoencephalitis decreased to 432 cases $(9.3 \%)$, a $50 \%$ drop. In the first years of the present study, there were approximately 60 hospital admissions for meningoencephalitis each year. This number fell progressively to 10 admissions per year in 2015 and none in 2016. Lethality was $8 \%$, well below the $23 \%$ found by Setúbal et al. ${ }^{2}$. However, these numbers cannot be compared, since Setúbal et al. ${ }^{2}$ studied only meningococcal meningitis. In the present study, meningoencephalitis affected older age groups, especially adults over 29 years old, while Setúbal et al. ${ }^{2}$ described $79.0 \%$ of the admissions for meningococcal disease in children under 15 years old. This difference can be explained by the relatively recent implementation of vaccines against meningoencephalitis in the National Immunization Program, benefiting only the younger generations.

The decrease in the number of admissions due to meningoencephalitis reflected, albeit in lower numbers, the reduction of registered cases in the municipality of Niteroi (unpublished data by the Coordenacao de Vigilancia em Saude de Niteroi). This decrease was the result of several vaccination campaigns ${ }^{1}$.

Despite their lower incidence in the elderly, meningoencephalitis had a high case-fatality rate in this age group. The case-fatality rate was $60 \%$ in patients older than 69 years and approximately 10\% in younger age groups. This agrees with the findings of Cabellos et al. ${ }^{11}$ who studied the outcomes of community-acquired bacterial meningitis for 30 years and found higher case-fatality rates in elderly patients.

Tomassini et al. ${ }^{12}$ described the changes in mortality in Niteroi between 1979 and 1997. The authors attributed the reduction of infectious diseases to a conjunction of factors, among them, the implementation of oral rehydration, the increase in coverage achieved by the PNI, the implementation of the Nutritional Surveillance System (SISVAN), the expansion of basic sanitation in some areas and more effective control of some endemic diseases ${ }^{12}$.

Tuberculosis was one of the few infectious diseases in which the number of cases tended to increase during the present study period. An increase in the number of hospital admissions due to tuberculosis in patients with and without AIDS was observed in 2012. Although modest, this increase is in contradiction with data published by the Brazilian Ministry of Health ${ }^{13}$, according to which there was a small but progressive decrease in the number of confirmed cases of tuberculosis in Brazil in general and in the Rio de Janeiro State in particular. Rio de Janeiro State experienced a progressive decrease in cases of 
tuberculosis, from 16,968 cases in 2001 to 13,766 cases in $2017^{14}$. This reduction was attributed by WHO to an increase in the budget for the National Tuberculosis Control Program ${ }^{14}$. This budget remained at an acceptable level until 2013, when it began to decline gradually until 2016. The unexplained increase in hospitalizations for tuberculosis may be attributable to a specific demand for hospitals with rooms adapted to prevent airborne infections. Tuberculosis was also one of the most incident opportunistic illnesses reported in the study of Coelho et al. ${ }^{15}$ carried out in Rio de Janeiro.

The number of hospital admissions for leptospirosis has decreased only in the last 10 years, possibly as a result of improvements in urban stormwater management and sanitation. However, this effect was not as strong as the one attributable to the National Immunization Program and the decrease in the number of hospitalizations for leptospirosis which was less impressive when compared to the decrease in the number of hospital admissions for vaccine-preventable diseases. It is possible that the target population served by our HUAP has been less impacted by the aforementioned urban improvements. The most important reduction in the number of hospital admissions for leptospirosis in the last ten years of the study period is in agreement with the statistical data on leptospirosis concerning the municipality as a whole (unpublished data by the Coordenacao de Vigilancia em Saude de Niteroi).

A curious finding regarding leptospirosis in the present study was its higher case-fatality rate (16.3\%) compared to the previous study performed by Setúbal et al. ${ }^{2}(10.2 \%)$. This may be an effect of the recently described severe pulmonary forms of leptospirosis. These pulmonary forms are not always jaundiced and are often complicated by Adult Respiratory Distress Syndrome, and their sudden advent in the last 20 years represents an intriguing and inexplicable change in the secular clinical picture of leptospirosis ${ }^{16}$. The present study showed that the older the patient, the higher the leptospirosis case-fatality rate, which ranged from $10.5 \%$ in patients aged 20 to 29 years and $20.5 \%$ in patients aged 40 to 49 years, and $28.6 \%$ in patients aged 50 to 59 years. These findings agree with the ones of Setúbal et al.'s study², which found twice as high case-fatality rates in the age group between 50 and 59 years $(23.1 \%)$ compared to patients between 40 and 49 years old (10.3\%). Setúbal et al. ${ }^{2}$ reported 123 hospital admissions for typhoid fever from 1965 to 1994. In the present study, there were only three hospitalizations: one in 1997, one in 1998 and one in 2003, probably reflecting as in the case of leptospirosis, improved sanitation and the drinking water supply.

Readmissions accounted for almost $20.0 \%$ of all hospital admissions and were often associated with
HIV-infected patients. However, they were less frequent after 2009, possibly because AIDS patients surviving the first opportunistic infections were increasingly able to regain immunity through combination antiretroviral therapy (cART). However, this positive effect of cART was not absolute; opportunistic infections were still the most frequent cause of hospitalization.

Considering that cART medicines are available for free, it is imperative and urgent to discuss the reasons for this ineffectiveness in the field (probably due to nonadherence) of such an efficient treatment. This is, however, beyond the scope of the present study. It should be mentioned that these patients often come from needy communities, and their demands go far beyond mere medical care.

The age groups of the studied population changed significantly, with a reduction in the proportion of children and adolescents and an increase in the proportion of adults and the elderly. Setúbal et al. ${ }^{2}$ reported that $55.9 \%$ of the patients were under 20 years old and only $9.2 \%$ were over 49 years old. In the first two years of the present study, the under -15 age group represented $27.0 \%$ of the 648 hospital admissions. In the last four biennia, it has represented less than $10.0 \%$, with only $2.8 \%$ of the 283 hospital admissions in the last biennium. As well as the reduction in vaccine-preventable diseases, this can be explained by the positive effects of the National Immunization Program, as vaccine-preventable diseases mainly affect children and the young. In the first two years of the present study, the number of patients aged 60 years or over was $52,8.0 \%$ of the 648 cases admitted in the same period. Over the past two years, the percentage has increased to $34.3 \%$ (97 of all 283 admissions). This increase in the proportion of elderly patients accompanied changes in the hospitalization profile during the two decades of the present study. In addition to the decrease in the number of hospital admissions for vaccine-preventable diseases, there was also an increase in the number of admissions of highly complex cases, often complicated by old age and comorbidities, referred by neighboring hospitals. Hospital admissions for noninfectious diseases were the second most frequent in the present study. Some correspond to patients in whom an infection was initially suspected, and then ruled out. There are also cases in which the hospital bed was simply loaned to an overworked section of the hospital. Good nursing care in individualized rooms can sometimes favor the admission of some patients with non infectious diseases. These situations are not uncommon and are sometimes reported in the medical literature ${ }^{17}$. In the present study, the overall institutional mortality decreased from $16.9 \%$ in the first biennium to $5 \%$ in the last biennium. According to Setúbal et $a l^{2}$, the overall institutional mortality in 1965 was 
27 deaths per 100 hospitalized cases. This number gradually declined to $11.0 \%$ in 1983 due to the decreased incidence of vaccine-preventable diseases. After the onset of the AIDS epidemic, institutional mortality rose to $19 \%$ in 1988 . In the present study, the institutional mortality rate maintained this plateau high until 2004, when it finally resumed its fall, reaching $4 \%$ in 2016. Setúbal et $a l .^{2}$ found that institutional mortality was higher in extreme age groups, being the highest (37.8\%) in children under one year and the lowest $(9.4 \%)$ in patients aged 15 to 19 years. In the present study, mortality in children under one year was 5.5\%. From 1995 to 2016, the highest institutional mortality was that of patients over 69 years $(26.7 \%)$.

HIV infection reached its highest case-fatality rate (75.0\%) in 1987 and declined progressively until 1994, when this proportion reached $50.0 \%^{2}$. In the present study, the HIV infection case-fatality rate fell from $40.0 \%$ in 1995 to only $5.0 \%$ in 2016, the last year of this study. Free antiretroviral treatment began in 1991, but the beneficial effects were evident only in the milestone year of 1996, with the advent and universal distribution of cART, consisting of a combination of at least three antiretroviral drugs from at least two different drug classes. Since its introduction, the incidence of opportunistic diseases has been reduced by up to 12 times, and the case-fatality rate among AIDS patients has been reduced by almost 5 times. Similar results were also reported by Grinsztejn et al. ${ }^{19}$ and Domingues and Waldman ${ }^{20}$ who described a drastic drop in overall mortality rates caused by AIDS-related causes since the late 1980's in Rio de Janeiro and Sao Paulo. This study has limitations inherent in an observational study. Data were obtained retrospectively and, for some diseases, were considered incomplete. However, the loss of patients was negligible. Despite the political and administrative constraints imposed on hospital demand, the Infectiology Service has been able to show the behavior of infectious diseases in the city over the past two decades and to compare this behavior with those of the previous three decades. Prospective handwritten tabulation of nosological data maintained by the hospital since 1964 and the computerized routine registry established since 1993 were critical to ensure data reliability and uniformity.

\section{CONCLUSIONS}

This study was able to demonstrate public health achievements resulting from the development and enhancement of the National Immunization Program over 40 years. These achievements were manifested by impressive reductions in the demand for vaccine-preventable diseases, as reported by Setúbal et al. ${ }^{2}$ and in the demand for meningoencephalitis, as demonstrated in the past 20 years. The present study was able to describe the decline of diseases such as leptospirosis and typhoid fever, preventable through urban and sanitation improvements. The institutional mortality fell sharply in the two decades studied, from $16.9 \%$ in the first biennium to 5.0\% in 2015 and 2016. In addition, the present study illustrated the sharp decline in the AIDS case-fatality rate after the beginning of cART.

\section{ACKNOWLEDGMENTS}

The authors gratefully acknowledge the general practitioners from the Infectiology Service of the HUAP/ UFF, Niteroi, Rio de Janeiro State, Brazil, for their clinical support.

\section{AUTHORS' CONTRIBUTIONS}

Laura da Cunha Ferreira: contributed to the study planning, data collection, analysis and interpretation of the results, statistical analysis and manuscript writing; Sérgio Setúbal: contributed to the study planning, analysis and interpretation of the results and manuscript writing; Luiz Sérgio Keim: contributed to the study planning, data collection and manuscript writing; Solange Artimos de Oliveira: contributed to the study planning, analysis and interpretation of the results, statistical analysis and manuscript writing. All authors revised the manuscript and approved the final version.

\section{CONFLICT OF INTERESTS}

The authors declare no conflicts of interests.

\section{FUNDING}

This study was financed in part by the Coordenacao de Aperfeicoamento de Pessoal de Nivel Superior (CAPES), Brasil - Finance Code 001.

\section{REFERENCES}

1. Brasil. Ministério da Saúde. Programa Nacional de Imunizações: 40 anos. Brasília: Ministério da Saúde; 2013. [cited 2019 Jun 25]. Available from: http://bvsms.saude.gov.br/bvs/ publicacoes/programa_nacional_imunizacoes_pni40.pdf

2. Setúbal S, Tavares W, Oliveira SA. Influence of immunopreventable diseases and AIDS on the demand of an infectious diseases department in Rio de Janeiro State, Brazil, in the course of thirty years (1965-1994). Rev Inst Med Trop Sao Paulo. 1998;40:185-92. 
3. Upshur RE, Moineddin R, Crighton E, Kiefer L, Mamdani M. Simplicity within complexity: seasonality and predictability of hospital admissions in the province of Ontario 1988-2001, a population-based analysis. BMC Health Serv Res. 2005;5:13.

4. Tsao HM, Sun C, Liou DM. A rational approach to estimating the surgical demand elasticity needed to guide manpower reallocation during contagious outbreaks. PLoS One. 2015;10:e0122625.

5. Brasil. Ministério da Educação. Empresa Brasileira de Serviços Hospitalares. Hospital Universitário Antonio Pedro - HUAPUFF: história. [cited 2019 Jun 25]. Available from: http://www. ebserh.gov.br/web/huap-uff/historia

6. Brasil. Ministério da Saúde. Secretaria de Vigilância em Saúde. Coberturas vacinais no Brasil: período 2010-2014. Brasília: Ministério da Saúde; 2015. [cited 2019 June 25]. Available from: http://portalarquivos2.saude.gov.br/images/ pdf/2017/agosto/17/AACOBERTURAS-VACINAIS-NOBRASIL---2010-2014.pdf

7. Oliveira SA, Setúbal S, Tavares W. Sarampo. In: Tavares W, Marinho LA, editores. Rotinas de diagnóstico e tratamento das doenças infecciosas e parasitárias. $4^{\mathrm{a}}$ ed. São Paulo: Atheneu; 2015. p.970-7.

8. Oliveira SA, Siqueira MM, Camacho LA, Nogueira RM, Spinetti CC, Garcia RC, et al. The aetiology of maculopapular rash disease in Niterói, State of Rio de Janeiro, Brazil: implications for measles surveillance. Epidemiol Infect. 2001;127:509-16.

9. Pacheco FC, França GV, Elidio GA, Oliveira CM, Guilhem DB. Decrease in the coverage of measles-containing vaccines and the risk of reestablishing endemic transmission of measles in Brazil. Int J Infect Dis. 2019;82:51-3.

10. Brasil. Ministério da Saúde. Secretaria de Vigilância em Saúde. Informe epidemiológico: coqueluche. Brasília: Ministério da Saúde; 2018. [cited 2019 Jun 25]. Available from: http:// portalarquivos2.saude.gov.br/images/pdf/2018/dezembro/18/ Informe-epidemiol--gico-da-Coqueluche.\%20Brasil,\%20 2016\%20a\%202017.pdf

11. Cabellos C, Verdaguer R, Olmo M, Fernández-Sabé NF, Cisnal $\mathrm{M}$, Ariza $\mathrm{J}$, et al. Community-acquired bacterial meningitis in elderly patients: experience over 30 years. Medicine (Baltimore). 2009;88:115-9.
12. Tomassini HC, Alves MG, Claro LB, Pacheco AG, Almeida MT. Evolução da população e da mortalidade em Niterói, Rio de Janeiro, Brasil, 1979 a 1997. Cad Saude Publica 2003;19:1621-9.

13. Brasil. Ministério da Saúde. DATASUS. Tuberculose: casos confirmados notificados no Sistema de Informação de Agravos de Notificação - Rio de Janeiro. [cited 2019 Jun 25]. Available from: http://tabnet.datasus.gov.br/cgi/tabcgi.exe?sinannet/cnv/ tubercrj.def

14. World Health Organization. Tuberculosis (TB): tuberculosis data. [cited 2019 Jun 25]. Available from: http://www.who.int/tb/ data/en/

15. Coelho L, Cardoso SW, Amancio RT, Moreira RI, Campos DP, Veloso VG, et al. Trends in AIDS-defining opportunistic illnesses incidence over 25 years in Rio de Janeiro, Brazil. PLoS One. 2014;9:e98666.

16. Pereira JC, Grijó A, Mackay AM, Vitral BG. Leptospirose pulmonar. Rev Port Pneumol. 2007;13:827-39.

17. Sinha SS, Sjoding MW, Sukul D, Prescott HC, Iwashyna TJ, Gurm HS, et al. Changes in primary noncardiac diagnoses over time among elderly cardiac intensive care unit patients in the United States. Circ Cardiovasc Qual Outcomes. 2017;10:e003616.

18. Coelho LE, Cardoso SW, Amancio RT, Moreira RI, Ribeiro SR, Coelho AB, et al. Predictors of opportunistic illnesses incidence in post combination antiretroviral therapy era in an urban cohort from Rio de Janeiro, Brazil. BMC Infect Dis. 2016;16:134.

19. Grinsztejn B, Luz PM, Pacheco AG, Santos DV, Velasque L, Moreira RI, et al. Changing mortality profile among HIVinfected patients in Rio de Janeiro, Brazil: shifting from AIDS to non-AIDS related conditions in the HAART era. Plos One 2013;8:e59768.

20. Domingues CS, Waldman EA. Causes of death among people living with AIDS in the pre- and post-HAART eras in the city of São Paulo, Brazil. Plos One. 2014;9:e114661. 